\title{
Creating Effective Mobile Apps for \\ National Geoparks. An Explorative Study
}

\author{
Thomas Kisser ${ }^{1}$ and Stefanie Zecha² \\ Gymnasium Bondenwald, Hamburg, Germany \\ Catholic University Eichstätt-Ingolstadt, Germany
}

\begin{abstract}
In order to attract visitors, National Geoparks propose different approaches, such as geotrails or guided tours. At the same time, there is a growth in the use of apps among the general population, for learning and information-gathering purposes, due to the everincreasing advances in smartphone technology. So far, however, National Geoparks have lagged behind in tapping into the growing use of smart devices. There is little integration of apps into their programs and tours. This article focuses on the use of apps within National Geoparks where it does occur. We examine the discussion of apps in recent literature, and learning processes using apps during field excursions. Out of this, the following question arises: What characteristics should a National Geopark app have in order to maximize learning outcomes? To answer this question, we used a qualitative interview study, and present both the results and ideas for possible future investigations.
\end{abstract}

\section{Keywords:}

apps, National Geopark, mobile learning

\section{Introduction: National Geoparks and new media}

Within their boundaries, National Geoparks have features or areas that are of particular interest, for example the Luisenburg-Felsenlabyrinth in the Nationalgeopark Bayern Böhmen, Germany. Different methods are used to attract visitors and provide people with different learning opportunities. National Geoparks are slowly catching on to smartphone technology, but there is room for more useful apps. Apps are handy because people tend to take their smartphones everywhere and can thus become involved easily in independent learning. So far, only a few National Geoparks in Germany utilize apps in their territory, and there are currently no articles on the theoretical background of the construction of an app for National Geoparks. An important question for researchers must surely be: What characteristics should a National Geopark app have in order to maximize learning outcomes?

We used a qualitative, semi-structured interview study to answer this question. 


\section{$2 \quad$ Creating an appropriate app}

\section{Brief Literature Overview of Apps and National Geoparks}

The academic literature on the subject of apps is still quite young. The German journal Praxis Geographie published the first articles on the use of apps in German geography teaching in 2014. Höhnle (2014), for example, presents a collection of apps which can be used in the classroom. Hennig and Vogler (2016) analyze how young users can be involved in the process of creating a webmap application.

In the field environmental education, a number of studies discuss the use of apps for observing animals. Yocco, Danter \& Heimlich (2011) evaluated apps in relation to animal behavior in zoos. With reference to National Geoparks specifically, Haller and Klas (2015) present the development and evaluation of an app for the Swiss National Park. Edwards and Burghardt (2005) describe the technicalities of how to make data on different aspects of National Geoparks visible for visitors within an app.

There is currently no literature which discusses the specific characteristics of an App for National Geoparks. This article is an attempt to close that gap.

\section{National Geoparks and pedagogical methods}

\section{What is a National Geopark?}

A National Geopark is a territory with geological features that are exceptional in terms of their scientific quality or rarity. In addition, to qualify as a National Geopark, the area must have an educational value for visitors. The aim of National Geoparks is to highlight not only geodiversity, but also cultural aspects, such as the influence of human beings on landscapes. The particular aims of National Geoparks in Germany are:

- explanation of the underlying geology of the specific area, including its relationship with the centre of the earth and the earth's crust;

- protection of the geological heritage with the help of sustainable land use and environmental education;

- support and promotion of scientific investigations and teaching within the National Geopark (ifl-Leipzig, 2016, p. 8).

In order to support and promote scientific research, National Geoparks use various teaching methods and educational tools.

\section{Pedagogical methods in National Geoparks}

One essential aspect of teaching geology is observation of phenomena through direct contact with a geosite (Birkenhauer, 2006). National Geoparks provide an ideal opportunity to implement this. They use different methods, such as guided tours or presentation boards, and most have specific geotrails, which focus on individual geosites, or geological and geomorphological sites of interest. A good example would be the Volcano Experience Path in the Vulkan Eifel National Geopark. 
Field trips are known to be of primary importance for learning about geology. Indeed, successful learning can only really occur in combination with outdoor learning activities. At particular geological sites, supervised by a guide and with the help of appropriate teaching methodology, one can gain valuable first-hand experience of geology. (Loss, 2006). Visual presentations such as graphs and photographs can help to bring a landscape to life. Geomedia, including apps, are increasingly being used in National Geoparks to disseminate information.

\section{Mobile learning with the help of apps in a National Geopark}

In general, mobile learning means learning via mobile devices such as smartphones. However, "Early definitions of [mobile learning], which focused predominantly on the attributes of mobile technology, have given way to more sophisticated conceptualizations suggesting that mobility is the central issue' (Winters, 2006). 'Mobility denotes not just physical mobility but also the opportunity to overcome physical constraints by having (virtual) access to people and digital learning resources, regardless of place and time' (Kukulska-Hulme, 2010, p. 181). Mobile learning also offers the possibility of authenticity and learning in an original context: with the help of mobile learning, you can collect information directly in nature and evaluate it, in line with the requirements of location-based learning (Kynäslahti, 2003).

Few National Geoparks use apps within their educational programs; those that do are very new to their use. It is also for this reason that there is so little literature on the subject. In this context, the following research questions emerged:

- What are the particular characteristics of an app designed specifically for excursions in National Geoparks?

- How are these apps different from existing apps that are used in National Geoparks?

\section{$3 \quad$ Methods}

\section{Empirical Research Design}

The empirical research design used is illustrated in Figure 1. The decision for a purely qualitative design was made because of the social significance of apps and learning processes during excursions, especially in National Geoparks, and because to date there have been no studies of the relation between apps and learning processes in National Geoparks. Our data consist of interviews and existing apps, belonging to and designed for use in specific Geoparks, aimed at enhancing learning processes in National Geoparks. 

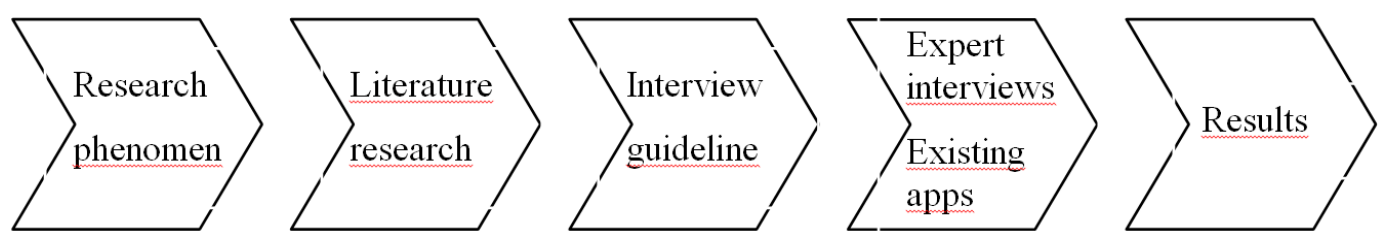

Figure 1: Research Design

\section{Sample of interview partners and interview format}

The purpose of the interviews was to focus on the relation between apps and learning processes during excursions, especially in National Geoparks. For this reason, we chose a qualitative, explorative investigation perspective. As a consequence, gaps in this investigation field can now be closed.

Interviewing experts is the main part of this investigation, to gain new information and to close gaps in the scant literature. The definition of 'expert' depends on the investigational interest (Meuser \& Nagel, 1991, p. 443). Our selection of interviewees was therefore made using a broad set of criteria. 'Experts' in this context represent the user perspective: they are National Geopark visitors with or without children, and teachers. Hence adult visitors, teachers and the managers of National Geoparks decide whether an app will be used for an excursion or not, because these groups can be expected to have the expert pedagogical and technological knowledge to conduct excursions.

Three trainee teachers (students with a degree who were going to be teachers within the next few months), specializing in E-learning and M-learning, took part in a group interview to maintain different points of view and argument through the discussion. Visitors to a National Geopark and Managers of Geoparks were interviewed separately (Table 1). The point of view of those National Geoparks which already have an app and those that do not were also discussed in interviews. We excluded pupils from the investigation. The various types of experts were chosen in order to obtain more comprehensive information. There are no personal connections between the authors and these persons. 
Kisser \& Zecha

\begin{tabular}{|l|l|l|}
\hline $\begin{array}{l}\text { Interview } \\
\text { partner }\end{array}$ & Characteristics of the interview partner & $\begin{array}{l}\text { Interview } \\
\text { situation }\end{array}$ \\
\hline $1-3$ & Trainee teachers specializing in E-learning and M-learning & $\begin{array}{l}\text { Group } \\
\text { interview }\end{array}$ \\
\hline 4 & $\begin{array}{l}\text { Visitor to the National Geopark Bergstraße-Odenwald, male, } \\
38 \text { years, 2 children }\end{array}$ & $\begin{array}{l}\text { Individual } \\
\text { interview }\end{array}$ \\
\hline 5 & $\begin{array}{l}\text { Visitor to the National Geopark Bergstraße-Odenwald, male, } \\
29 \text { years }\end{array}$ & $\begin{array}{l}\text { Individual } \\
\text { interview }\end{array}$ \\
\hline 6 & $\begin{array}{l}\text { Visitor to the National Geopark Bergstraße-Odenwald female, } \\
44 \text { years }\end{array}$ & $\begin{array}{l}\text { Individual } \\
\text { interview }\end{array}$ \\
\hline 7 & $\begin{array}{l}\text { Manager of the National Geopark Ruhrgebiet, a National } \\
\text { Geopark without an app }\end{array}$ & $\begin{array}{l}\text { Individual } \\
\text { interview }\end{array}$ \\
\hline 8 & $\begin{array}{l}\text { Manager of the National Geopark Nordisches Steinreich, a } \\
\text { National Geopark without an app }\end{array}$ & $\begin{array}{l}\text { Individual } \\
\text { interview }\end{array}$ \\
\hline 9 & $\begin{array}{l}\text { Manager of the National Geopark Bergstraße-Odenwald, a } \\
\text { National Geopark with an app }\end{array}$ & $\begin{array}{l}\text { Individual } \\
\text { interview }\end{array}$ \\
\hline
\end{tabular}

This is an explorative study only. For this reason, the number of interviews was limited, as gaining information rather than a high number of responses was more important: the number of interviews was designed to gather as much information as possible. At the same time as the interviews were being conducted, we started to analyse them in order to see whether they were yielding new information or not. When we saw that no further new information was being gained, we stopped the interview process. The interviews took place between November 2015 and June 2016.

\section{Interview guideline}

The interviews followed a specially designed guideline for the specific interview partners, and were semi-structured, with open-ended questions (Flick, 1992). The interview guideline was developed based on suggestions from the literature (theoretical section).

- The first part deals with the attempts to determine interviewees' current experience with apps in general and in relation to National Geoparks in particular.

- The second part focuses on the learning process, covering aspects of problem-based learning or micro-learning in National Geoparks.

- The third part covers the use of apps, focusing on technical aspects, user groups and app design.

- In the fourth part, experts are asked to make predictions about future trends in the use of apps during excursions, especially to National Geoparks. 
The interviews with the authorities of the National Geoparks followed a slightly different structure in the first section. The National Geopark with its own app (interview partner [P] 9 in Table 1) told us about their app. The National Geoparks without apps (P7, P8) were asked to talk about their plans for an app or, if there were no actual plans (P7), they should talk about their ideas for one.

The interview guidelines enable orientation of the discussion so that the results are comparable (Gläser \& Laudel, 2006, p. 39 et seq.). Each interview was transcribed and kept in the participant's own words to reflect the interview as closely as possible.

\section{National Geopark Bergstraße-Odenwald app: short presentation}

The startscreen is the same as the menu and resembles a compass. Via the menu, one can access twelve different functions:

- About us: information about the National Geopark, including a map.

- Visitor centres: the entrances, information centers and environmental learning stations are described.

- Ranger: offers for adults and children can be provided, but there is no information yet.

- Restaurants: restaurants and cooperating partners can be listed, but there is no information yet.

- Parking lots: all parking lots are listed in alphabetical order. The parking lots are located by turning the smartphone.

- Accommodation: eight different types of accommodation are listed in alphabetical order. The accommodation can be located by turning the smartphone.

- World Heritage Sites: the Messel Pit and the Abbey of Lorsch are mentioned. They can be located by turning the smartphone.

- Sponsors: eight sponsors are listed.

- Game: a memory game with different pictures of nature is provided.

- Webcam: four different views had been provided, but had been disabled.

- Camping and barbecues: sites for camping and barbecues are listed, located by turning the smartphone.

- Dates: the latest organized activities are listed.

Under the compass, there is a quick menu for the latest dates and information for cyclists and walkers. The information for cyclists and walkers is not yet available. The National Geopark Odenwald's app was chosen as an example (the National Geopark Bayern-Böhmen has an app as well) because this particular Geopark is in easy reach for one of the authors. 


\section{$4 \quad$ Results}

In this section, the most interesting results are presented. Quotations from the interviews are presented which go some way towards describing the apps and answering our research questions:

- What are the particular characteristics of an app designed specifically for excursions in National Geoparks?

- How are these apps different from existing apps that are used in National Geoparks?

\section{The National Geopark Bergstraße-Odenwald app}

The interview partners using the National Geopark Bergstraße-Odenwald's app were disappointed by it. Although the handling was easy (P6, $\$ 4)$, two partners stated that 'the app does not give the user anything' (P4, \$8; P5, \$4), since it is a map, which shows hiking trails, Geopoints, restaurants, parking lots and the other services of the National Geopark Bergstraße-Odenwald (Geoparkranger). However, this is exactly the information which the app should provide. The user can locate him/herself via GPS and search the map for points of interest, and can also inform him/herself about the offers of the National Geopark (P9, $\$ \$ 4,10,22)$.

There are several reasons, from the perspective of the National Geopark BergstraßeOdenwald, why the app is the way it is. First, the app's developer had already created several apps for cities, giving the user advice on where buildings, restaurants or other points of interest are (P9, \$20). Showing the location of items represents the developer's routine work. In addition, ongoing support and development for the app would be very demanding and therefore costly (P9, \$37). A more expensive, better curated app would be unaffordable. As a result, the app is not very closely aligned with the ethos of a National Geopark (P), $\$ \$ 47$, 49).

\section{Targeted user groups}

The trainee teachers and two of the authorities of the National Geoparks differentiated between user groups: students, teachers, tourists, and people interested in science (P2, \$142); families, tourists, and people interested in science (P7, \$10); younger people and people interested in science (P8, \52). Each group should get its own targeted app, edited in terms of the language used and materials. The tourists and one National Geopark manager thought that one app for adults $(\mathrm{P} 4, \S 24)$, or for children and teenagers $(\mathrm{P} 6, \$ 8)$, or for the middleaged $(\mathrm{P} 7$, \$31) should be targeted. However, the fit of app to target group is seen as a major problem (P3, \$157; P5, \$24; P6, \$16).

\section{Geopoints and local aspects}

All interviewees felt that the particular Geopoints within the National Geoparks were the most important things about the Geoparks and thus should be the main focus of the app $(\mathrm{P} 1, \S 110 ; \mathrm{P} 4, \S 36 ; \mathrm{P} 5, \S 30 ; \mathrm{P} 6, \$ 20)$. If there is a connection between the different 
Geopoints, this connection should be made clear (P2, \$133; P4, §46; P5, §40; P6, §28; P8, $\$ 32)$. However, a thematic connection is not always possible (P8, \$32), and some interview partners preferred a less guided approach, so that individual combinations of Geopoints for each visitor would be possible (P2, \$133; P7, §42; P8, \32).

\section{Preparation and starting area}

The tourists interviewed said that they were not interested in finding out about what the National Geopark had to offer in advance of visiting it, or as regards the contents of the app (P4, \$40; P5, \$34; P6, \$24). The trainee teachers highlighted the need to know about the thematic and subject-specific content of the Geopark, and of the Geopark's app, before going on a field trip, in order to make full use of the app's potential (P1, \$118; P3, \$117).

The first area to visit covered by the app should give a good overview of what the National Geopark offers (P2, \42; P3, \36; P7, \36; P8, \42). The trainee teachers stated that the entrance area, the first area to be visited, is crucial for the success of the field trip (P1, \$124).

\section{Pedagogical aspects of the app}

To get the thematic content across to the user, the app should use

- either short videos or audios (P2, \$108; P5, \$14; P8, \$38),

- or (animated) figures (P4, \$28; P8, \$38).

- The interview partners stated unanimously that there should be as little text as possible (P2, \110; P4, \28; P5, \20).

- Short phrases or striking juxtapositions of images are held to be good (P8, \$38).

The information is best imparted within the context of a problem which has to be solved during the field trip (P1, §89; P2, §91; P3, §90; P4, §30; P5, §22; P6, §14).

The teachers would like the app to guide students in doing empirical research or to use scientific research methods using their smartphone (P1, $\$ 55,61 ; \mathrm{P} 2, \$ 58,60)$. If a smartphone is used to measure something, then its accuracy should be compared to that of scientific tools (P1, \55; P2, $\ \ 53,80,82$; P3, $\ \$ 52,54,81,83)$. The National Geopark authorities claim that a personal guide can tailor the level of difficulty to the individual group and respond to special questions, which is something that an app cannot do (P), $\iint 9,16$; P8, \$30). One of the tourists did not want tasks, because that would be too similar to school lessons (P4, \$26). The other two tourists thought that tasks would be helpful as support (P5, \18; P6, \$10).

The users unanimously stated that

- The app should be easy to use, stable, provide information quickly, and should not distract but assist the user (P2, $\$ \$ 30,34,43$; P3, $\$ 29 ; \mathrm{P} 4$, $\$ \$ 20,38$; P5, $\$ \$ 10,12,14)$.

- A map to orient oneself would be useful $(\mathrm{P} 5, \S 48)$. 
- At the individual Geopoints, the app should enhance the Geopoints with information that is not obvious in the analogue world $(\mathrm{P} 3, \S 31)$.

One teacher preferred strict guidance for students, so that they stick to the task and are routed to interesting points $(\mathrm{P} 1, \$ 35)$. Another teacher had a totally different view, asking for open, explorative learning situations (P3, §44).

The individual tasks should take as long as necessary $(\mathrm{P} 6, \mathbb{\$} 22)$, or not more than one hour $(\mathrm{P} 5, \S 32)$, and not delve too deep into theory $(\mathrm{P} 4, \$ 38)$.

\section{Last stop and results}

At the last stop within the National Geopark, the interview partners would like to see a short summary (P1, \$135; P2, \$136; P4, §48; P5, \$42; P6, \$32). In addition, the connection between the app's contents and the scientific work of the National Geopark could be made made transparent $(\mathrm{P} 2, \S 36)$.

The trainee teachers and one of the visitors held the view that it is not always necessary for there to be a learning outcome at the end of the learning module $(\mathrm{P} 1, \$ 96)$. The results can be written down analogue (P2, \$68). Since P4 was against tasks, he was also against recorded learning outcomes.

In the opinion of the National Geopark authorities and visitors, either at each Geopoint or at the end of the tour,

- the results gathered using the app should be checked, in order to check the quality of the work (P5, \28; P6, \18; P7, \$28; P8, \46).

- the results could be sent to the participants as a digital report $(\mathrm{P} 1, \$ 70)$. This report could include a certificate with individual feedback for the participant (P2, \$140; P6, \$32).

- photos or videos taken could be geo-tagged and be part of the results (P2, §98; P3, $\$ 67, \$ 68)$.

However, where non subject-specific competencies like personal competencies, social competencies or attitude (Ziener, 2008, pp. 58, 79, 135) are concerned, not every lesson learned can be checked $(\mathrm{P} 3, \$ 97)$.

\section{Operating system and mobile internet}

When it comes to the technological requirements, all interviewees agreed about the platform on which the app should run. A mobile internet connection should not be necessary, because in the rural areas of the National Geoparks, mobile internet is either slow or unavailable (P4, \$54; P7, §48; P9, \$60). A mobile internet connection could become a major problem if it was needed to run the app $(\mathrm{P} 1, \$ 151 ; \mathrm{P} 4, \$ 31)$. To popularize the app as widely as possible, it should be developed for both iOS and Android (P9, \41), as these are the most common platforms (P2, \$159; P7, \$46; P8, \56). 


\section{Outlook: the future of apps}

The interview partners' outlook on the future of apps in National Geoparks is twofold. On the one hand, the users as consumers all claim that the further extensive development of apps is inevitable (P2, \165; P4, \56; 5, \48; P6, \36). However, the visitors to the National Geopark regret this foreseen development, because they reject the use of digital mobile devices in nature $(\mathrm{P} 4, \$ 12,13,14 ; \mathrm{P} 5, \S 18 ; \mathrm{P} 6, \$ 36)$. Interestingly, the teachers think it is necessary to use these devices and apps to keep pupils interested and motivated (P2, \$165).

The National Geoparks as providers stated unanimously that an app is or would be a good thing to have, and it would be nice to develop the app further, but the importance of apps is only minor $(\mathrm{P} 7, \S 4 ; \mathrm{P} 8, \S 62 ; \mathrm{P} 9, \S 47,49)$. However, there could be a simple reason why apps should be developed for use in National Geoparks. As P8 said, there is a need for an interface between the National Geopark and (potential) visitors. People generally do not purposefully search for geology; they do not know the trigger words. Hence the interface would bring the geology to them (P8, \$22).

\section{$5 \quad$ Results and discussion}

\section{In relation to the investigation's design}

A variety of interview partners were chosen in order to get insights into the points of view of teachers who could use the app with pupils, adults with and without children who could use the app, and the authorities of the National Geoparks as providers of the product app. For further investigations, a quantitative research design would be useful in order to verify the data acquired in this study. The advantage of our qualitative research design was that the interview partners had the opportunity to justify their statements.

\section{In relation to the results}

First, the difficulties. People's expectations of a National Geopark app tend to be higher than for a city app. They do not just want to know the location of hiking trails, Geopoints or National Geopark rangers' offices. These people are also interested in information about the sites of interest in the park. A good example of this is the app for the National Park BayernBöhmen, which offers information for tourists about the special Geopoints, advises on good places for lunch, and provides other specially-targeted information.

Based on our findings, National Geoparks should consult the different potential users of an app to gain insights into their interests. In this way, resistance to using an app could be lowered (Haller \& Klas, 2015).

For the owners of the apps, production and maintenance costs are of utmost importance. One solution to this problem would be for National Geoparks to look for agencies which are qualified in this specific field.

App creators should take into account the fact that there are different user groups. One possibility would be to make an app for each group. Normally in National Geoparks, the 
cost of designing several user-targeted apps is prohibitive. For this reason, another possibility would be that all visitors use the same app, but the app should include sections tailored to the different groups - for example, a section for use during school trips.

Some app users will want to know in advance how the app works - for example, teachers preparing their class trip. This goes along with the pedagogical aspect of a class excursion (Rinschede, 2007). Most other users will not want to do any preparation and will want to use the app straight away on arrival at the National Geopark. For this second group, a short introduction when launching the app is enough to take in. The different perspectives of the various user groups should be further investigated. Haller and Klas (2015, p. 281) remark that the data in their investigation is anonymous and that they cannot give information about user habits, e.g. which features of the app they use most often, but this would be an interesting aspect to study.

The construction of the app is an important further aspect. The start and end points of the trail are key locations for learning. In the entrance area, the app should give a good overview of its content. With regards to achieving pedagogical aims, people respond best to short pieces of text and best of all to videos. At the end of the app trail, there should be a short summary and a link to further information. These apps could also integrate micro-based learning activities, i.e. focused learning nuggets of short duration. Teachers also want their pupils to use scientific methods during their visits to National Geoparks. These aspects are in line with the essential aspects of GPS education trails (Zecha, 2014). So far, however, apps have not really addressed the pedagogical aspects of learning situations.

From the technical perspective, the app should work independently of the internet, because remote locations tend not to have internet connections. Edwards and Burghardt (2005) also give this recommendation. The app must also take into account the different smartphone platforms. The perfect app has to cater to the questions and needs of different types of visitors (adults, children or school classes) and their learning perspectives, such the importance of the entrance area and the end area, as well as present the existing information about National Geoparks.

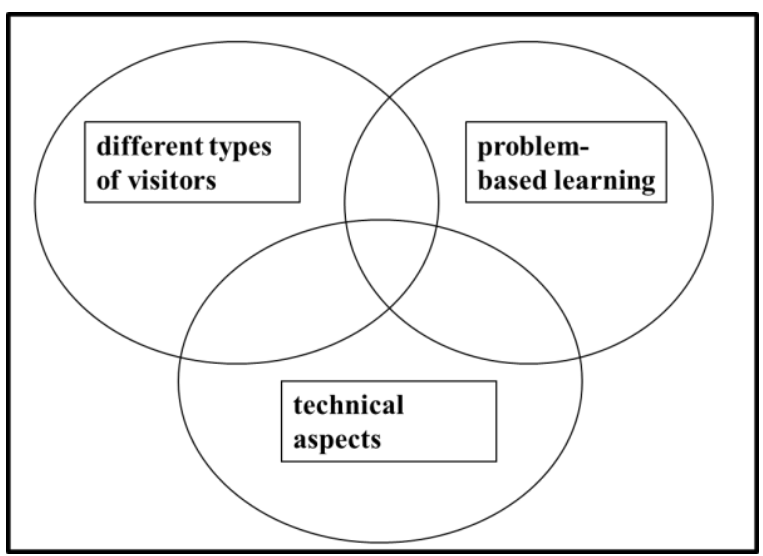

Figure 2: Different components of a perfect app for National Geoparks 


\section{Outlook}

The focus of this explorative study was to show which special characteristics an app should have for use in National Geoparks. The next step would be to create a quantitative questionnaire to evaluate the other apps that exist in German National Geoparks and in Europe more widely. Based on the experience gained in this investigation, it would be interesting to construct a prototype of the perfect app for a National Geopark and then to evaluate it.

\section{References}

Birkenhauer, J. (2006). Basics for geosciences education. 5th international meeting, geosciences education: understanding System Earth Bayreuth, 18-21 September 2006

Edwards, A.; Burghardt, D. (2005). Geo-enabling spatially relevant data for mobile information use and visualisation. In Li, K.; Vangenot, C. (Eds.), Web and wireless geographical information system. Wiesbaden. Springer Verlag, pp. 78-93

Flick, U. (1992). Triangulation Revisited. Strategy of or Alternative to Validation of Qualitative Data. Journal for the Theory of Social Behavior, 22, 175-197

Gläser, J.; Laudel, G. (2006). Experteninterviews und qualitative Inhaltsanalyse: als Instrumente rekonstruierender Untersuchungen. Wiesbaden. Springer Verlag

Haller, R.; Klas, U. (2015). iWebpark - mit mobiler Geoinformation unterwegs im Schweizerischen Nationalpark. In Hennig, S. (Ed.), Online Karten im Fokus, Heidelberg, Wiechmann, pp. 275-288

Hennig, S.; Vogler, R. (2016). User-centred map applications through participatory: Experiences gained during the 'YouthMap 5020' project. Cartographic Journal, 53(3), 213-229

Höhnle, S. (2014). Integration Mobilen Lernens in eine Unterrichtssequenz zum Globalen Lernen. Kritisch-reflexiver Umgang mit 'Nachhaltigkeitsapps' am Beispiel Palmöl. Praxis Geographie, 6, $42-46$

Ifl-leipzig (2015). Geoparks -Vielversprechende Kooperationspartner für Geographische

Gesellschaften?

(https://www.iflleipzig.de/fileadmin/user_upload/Forschung/Geovisualisierung/HR_Geoparks.pdf 17.11.2017)

Johnson, L., Levine, A., Smith, R., \& Stone, S. (2010). The 2010 Horizon Report. Austin, TX: The New Media Consortium

Kukulska-Hulme, A. (2010). Mobile learning as a catalyst for change. Open Learning: The Journal of Open and Distance Learning, 25(3), 181-185

Kynäslahti, H. (2003). In Search of Elements of Mobility in the Context of Education. In Kynäslahti, H. \& Seppälä, P. (Eds.), Mobile Learning. 48IT Press. Helsinki. 41.

Loss, G. (2006). Excursions and field trips as a core interactive method in school, university, extracurricular and adult earth science education. 5th international meeting geoscience education: understanding System Earth, Bayreuth, 18-21 September 2006

Meuser, M.; Nagel, U. (1991). ExpertInneninterviews - vielfach erprobt, wenig bedacht: ein Beitrag zur qualitativen Methodendiskussion. In Garz, D.; \& Kraimer, K., Methoden der vergleichenden Politik- und Sozialwissenschaft, Qualitativ-empirische Sozialforschung: Konzepte, Methoden, Analysen. Opladen, pp. 441-471

Rindschede, G. (2007). Geographiedidaktik, Weinheim, UTB Verlag

Vaala, S.; Ly, A.; Levine, H. (2015). A market scan and analysis of children's literacy apps Getting a read on the app stores. http://www.emarketer.com/Article/Smartphone-Users-Worldwide-WillTotal-175-Billion-2014/1010536\#sthash.lrDodp9i.dpf (14.06.2015) 
Winters, N. (2006). 'What is mobile learning?' In Sharples, M. (Ed.), Big Issues in Mobile Learning: Report of a workshop by the Kaleidoscope Network of Excellence Mobile Learning Initiative. Nottingham: University of Nottingham

Yocco, V.; Danter, E.; Heimlich, J.; Dunckel, B.; Myers, C. (2011). Exploring use of new media in environmental education contexts: introducing visitors' technology use in zoos model. Environmental Education Research, 7, 801-814

Zecha, S. (2014). Basics of an effective GPS education trail methodology. In Vogler, R.; Car, A.; Strobl, J.; Griesebner G. (Eds), GI_Forum 2014 - Geospatial Innovation for Society, Heidelberg, Wichmann Verlag, 352-362

Ziener, G. (2008). Bildungsstandards in der Praxis. Kompetenzorientiert unterrichten. Seelze-Velber: Kallmeyer

\section{Internet Links:}

http://www.geopark-bayern.de/Public/GeotourVulkane/GeotourVulkane.htm (22.1.2017) 